The FASEB Journal express article 10.1096/fj.03-0708fje. Published online December 19, 2003.

\title{
Regulatory role of C5a in LPS-induced IL-6 production by neutrophils during sepsis
}

Niels C. Riedemann, ${ }^{*}$ Ren-Feng Guo, ${ }^{*}$ Travis J. Hollmann, ${ }^{\dagger}$ Hongwei Gao, ${ }^{*}$ Thomas A. Neff,* Jayne S. Reuben, ${ }^{*}$ Cecilia L. Speyer, ${ }^{*}$ J. Vidya Sarma, ${ }^{*}$ Rick A. Wetsel, ${ }^{\dagger}$ Firas S. Zetoune, ${ }^{*}$ and Peter A. Ward*

*Department of Pathology, University of Michigan Medical School, Ann Arbor, Michigan 48109; and Institute of Molecular Medicine for the Prevention of Human Disease, University of Texas-Houston, Houston, Texas 77030

N. C. Riedemann and R.-F. Guo contributed equally to this work.

Corresponding author: P. A. Ward, M.D., Department of Pathology, University of Michigan Medical School, 1301 Catherine Road, Ann Arbor, MI 48109-0602. E-mail: pward@umich.edu

\section{ABSTRACT}

Experimental sepsis in rodents occurring after cecal ligation/puncture (CLP) is associated with excessive complement activation and a systemic inflammatory response. The proinflammatory mediator IL-6 has recently been shown to be an important inducer of the C5a receptor (C5aR) during sepsis. We now provide evidence that serum IL-6 production during sepsis in rats was reduced in neutrophil-depleted animals and that absence of C5aR in mice as well as antibodyblockade of $\mathrm{C} 5 \mathrm{a}$ in rats significantly reduced serum levels of IL-6 during sepsis. Lipopolysaccharide (LPS)-induced production in vitro of IL-6 by neutrophils was significantly enhanced in the co-presence of C5a, likely due to transcriptional up-regulation of IL-6. Production of IL-6 in neutrophils by LPS was NF- $\kappa B$ dependent (but not on the presence of p50) and dependent on phosphorylation of p38-mitogen activated protein kinase (MAPK) as well as p44/p42 MAPK (ERK1/2) but not on phosphorylation of c-Jun N-terminal kinases (JNK1/2). C5a stimulation of neutrophils elicited a rapid phosphorylation of ERK1/2 and p38 MAPK. Accordingly, we suggest that induction of IL- 6 after CLP is neutrophil and C5a/C5aR dependent, likely due to the ability of $\mathrm{C} 5 \mathrm{a}$ to cause activation of ERK1/2 and p38 MAPK signaling pathways.

Key words: complement • signaling • MAPK • CLP • PMN

omplement activation occurs after a variety of different stimuli. The classical pathway is activated by antigen-antibody complexes and requires nine complement proteins. The lectin pathway of complement activation is initiated by bacterial surface sugars (mannose) via interaction with mannose binding lectin (MBL) protein in serum and subsequent interaction with MBL activated serine proteases (MASPs), followed by engagement of C4 and $\mathrm{C} 2$. The alternative complement pathway is activated by bacterial LPS and related products. All complement activation pathways converge at the level of $\mathrm{C} 3$ and lead to the cleavage products, $\mathrm{C} 3 \mathrm{a}$ and $\mathrm{C} 5 \mathrm{a}$, as well as generation of the membrane attack complex, C5b-9. C5a is known to exert numerous proinflammatory effects such as chemotactic responses of neutrophils (1), 
release of granular enzymes from phagocytic cells (2), production by neutrophils of superoxide anion (3), vasodilatation, increased vascular permeability (4), and induction of thymocyte apoptosis during sepsis $(5,6)$.

During the onset of sepsis, there is accumulating evidence for excessive production of C5a in rodents and in humans $(7,8)$. In humans, $\mathrm{C} 5 \mathrm{a}$ has been described as a serum marker that correlates with the severity of sepsis (9). Recent reports provide compelling evidence for the beneficial effects for blockade of either C5a or C5a receptor (C5aR, CD88) in experimental sepsis $(6,10,11)$, suggesting a harmful role of $\mathrm{C} 5 \mathrm{a}$ in the outcome of sepsis.

IL-6 is a proinflammatory mediator, which has recently been demonstrated to be responsible for up-regulation of $\mathrm{C} 5 \mathrm{a}$ receptor $(\mathrm{C} 5 \mathrm{aR})$ in various organs during sepsis (12). It has been recently shown that blockade of IL-6 with antibodies at the start of cecal ligation/puncture (CLP) greatly improved survival in mice in a dose-dependent manner, in such way that too much or too little anti-IL-6 was detrimental for survival. These experiments suggested a complex positive feedback mechanism between IL-6 and C5a/C5aR activation during sepsis. Earlier reports with peripheral blood mononuclear cells or Kupffer cells suggested that LPS-induced IL-6 production was enhanced in vitro with addition of $\mathrm{C} 5 \mathrm{a}(13,14)$.

It is well known that inflammatory mediators like LPS induce NF- $\kappa \mathrm{B}$ activation in neutrophils (15) by employing signaling pathways that lead to phosphorylation of p38 mitogen activated protein kinase (MAPK) (16). In monocytes, activation of p44/p42 MAPK [also referred to as extracellular signal-regulated kinase (ERK1/2)] and c-Jun N-terminal kinases (JNK1/2) may be involved in IL-6 production (17). C5a appears to be involved in NF- $\kappa$ B activation in monocytes (18). There is limited information about the effects of C5a on the various signaling pathways in neutrophils and the involvement of $\mathrm{C} 5 \mathrm{a}$ in regulation of cytokine production, especially during sepsis. In the current study, we investigated the effects of C5a on LPS-induced IL-6 in vitro production in neutrophils and IL-6 levels in serum during CLP-induced sepsis. We also investigated the underlying signaling pathways to elicit by $\mathrm{C} 5 \mathrm{a}$.

\section{METHODS}

\section{Production of anti-C5a antibody}

The C-terminal end of rat C5a (sequence: CTIADKIRKESHHKGMLLGR) corresponding to the amino acids 58-77 was chosen for peptide synthesis, as described previously (19). The peptide was then coupled to keyhole limpet hemocyanin and used for the immunization of goats and production of anti-C5a. The anti-peptide specific antibody was affinity purified. Its crossreactivity with recombinant rat $\mathrm{C} 5 \mathrm{a}$ was confirmed in Western blots.

\section{Cloning and expression of rat $\mathrm{C5a}$}

Recombinant rat C5a was produced in our laboratory, using the pGEX expression vector for GST gene fusion (Amersham, Pharmacia Biotech, NJ) (5). 


\section{Experimental CLP-induced sepsis}

Specific, pathogen-free $300 \mathrm{~g}$ male Long Evans rats (Jackson Laboratories, Bar Harbor, ME) were used for the studies as indicated. Anesthesia was achieved by intraperitoneal injection of ketamine. In the CLP model, $\sim 1 / 3$ of the cecum was ligated through a $3 \mathrm{~cm}$ abdominal midline incision. The ligated part of the cecum was punctured through and through with a 21 gauge needle. After the bowel was repositioned, the abdomen was closed in layers, using a 4.0 surgical suture (Ethicon Inc., Somerville, NJ) and metallic clips. Where indicated, animals received intravenously $500 \mu \mathrm{g}$ anti-C5a IgG in $500 \mu \mathrm{l}$ Dulbecco's phosphate buffered saline solution (DPBS) immediately after CLP. Control animals received similar amounts of normal goat IgG. For studies in mice, CLP was performed similarly with exception of the ligation length, which was $\sim^{2 / 3}$ of the cecum. $\mathrm{C} \mathrm{aR}^{-/-}$mice and back crossed littermate control mice (on the background of C57B6) were generated and supplied by the laboratory of Dr. Rick Wetsel at the University of Texas. NF- $\mathrm{BB}$ knockout mice, lacking the subunit p50, were purchased from Jackson Laboratories.

\section{Neutrophil isolation from rat whole blood and in vitro stimulation}

Whole blood from rats was drawn from the inferior vena cava. Citrate was used as an anticoagulant (ACD from Baxter Health Care, Inc., Mundelein, IL). Neutrophils were isolated using Ficoll-Paque gradient centrifugation (Pharmacia Biotech, Inc., Uppsula, Sweden) and dextran sedimentation. Hypotonic red blood cell lysis was achieved using sterile $\mathrm{H}_{2} \mathrm{O}$. Neutrophils were resuspended in Dulbecco's Modified Eagle Medium (DMEM; BioWhittaker Inc., Walkersville, MD) containing $10 \%$ fetal calf serum. A final concentration of $4 \times 10^{6}$ cells $/ \mathrm{ml}$ was used for stimulation at $37^{\circ} \mathrm{C}$ for $2-4 \mathrm{~h}$ with C5a $(10 \mathrm{nM})$ or lipopolysaccharide (LPS, $\left.20 \mathrm{ng} / \mathrm{ml}\right)$, or both. Supernatants were collected after pelleting the cells and frozen at $-80^{\circ} \mathrm{C}$ until used for ELISA analysis. For certain experiments, neutrophils were preincubated for 30 min with $20 \mu \mathrm{M}$ of the NF- $\kappa$ B activation inhibitor Bay 11-7082 (Calbiochem, San Diego, CA), or with MEK1/2 inhibitor U0126 (Cell Signaling Technology, Inc., Beverly, MA) inhibiting ERK1/2 activation, or with p38 MAPK inhibitor SB 203580 (Upstate, Waltham, MA), or with (L)-JNK inhibitor 1 (peptide) or JNK inhibitor 2 SP600125 (Calbiochem, Biosciences Inc.). All concentrations were based on directions from the manufacturers.

\section{Isolation of mouse neutrophils}

For isolation of neutrophils in mice, animals were injected with $3 \mathrm{ml} 2.4 \%$ thioglycollate solution (Difco Laboratories, Detroit, MI). Five hours later, they were killed and a $1 \mathrm{~cm}^{2}$ patch of skin was dissected from the abdominal muscles. The peritoneal cavity was injected with $10 \mathrm{ml}$ of DPBS three times for retrieval of neutrophils. Neutrophils were than counted using a light microscope, centrifuged at $1800 \mathrm{rpm}$ for $8 \mathrm{~min}$, and resuspended in DMEM containing 10\% fetal calf serum.

\section{Collection of serum samples from septic animals}

After induction of sepsis, animals were killed at the indicated time points after CLP and blood was drawn from the inferior vena cava. Blood samples were allowed to clot at $5^{\circ} \mathrm{C}$ for $4 \mathrm{~h}$ before 
centrifugation at $4000 \mathrm{rpm}$ for $15 \mathrm{~min}$ at $4^{\circ} \mathrm{C}$. Serum was collected and immediately frozen at $80^{\circ} \mathrm{C}$ until used for ELISA analysis.

\section{Quantitation of IL-6 by ELISA}

IL-6 levels of supernatant fluids from rat or mouse neutrophils were determined using ELISA kits for rat/mouse IL-6 (Biosource Intl. Inc., Camarillo, CA), according to the instructions of the manufacturer. Various dilutions for supernatant fluids from LPS and LPS + C5a stimulated neutrophils were analyzed.

\section{Western blot analysis}

Neutrophils were isolated from healthy animals and stimulated at $37^{\circ} \mathrm{C}$ in vitro with $\mathrm{C} 5 \mathrm{a}(10$ $\mathrm{nM})$ or LPS $(20 \mathrm{ng} / \mathrm{ml})$ or both. Approximately $2 \times 10^{6}$ cells per condition were then used for whole cell lysis using Laemmli buffer containing 5\% mercaptoethanol. Lysates were separated on a NuPAGE 12\% Bis-Tris gel (Invitrogen Inc., Carlsbad, CA), and proteins were then transferred to a PVDF membrane. Membranes were incubated overnight with antibodies to various phosphorylated and nonphosphorylated MAPK (Cell Signaling Technology, Inc.). For detection of protein, enhanced chemiluminescence (ECL plus) was used (Amersham Pharmacia Biotech Inc., Piscataway, NJ) according to the instructions of the manufacturer.

\section{RT-PCR analysis for IL-6 gene transcription}

Neutrophils were isolated and stimulated in vitro with either C5a $(10 \mathrm{nM})$, LPS $(20 \mathrm{ng} / \mathrm{ml})$, or LPS + C5a. Total RNA was isolated from $\sim 20-30 \times 10^{6}$ cells per condition using the Trizol method (Life Technologies Inc., Rockville, MD). Digestion of any contaminating DNA was achieved by treatment of samples with RQ1 Rnase-free DNase (Promega, Inc., Madison, WI). Reverse transcription was performed with $5 \mu \mathrm{g}$ RNA, using the Superscript II RNase $\mathrm{H}^{-}$Reverse Transcriptase (Gibco BRL, Inc., Grand Island, NY). PCR was performed using primers, which detected a 561 bp section of the rat IL-6 gene (Biosource Intl. Inc.). Primers for detection of the "housekeeping" gene, GAPDH, were 5' primer, 5'-GCC TCG TCT CAT AGA CAA GAT G-3' and 3' primer, 5'-CAG TAG ACT CCA CGA CAT AC-3'. The RT-PCR product was confirmed by electrophoresis of samples in $1.2 \%$ agarose gel. Control experiments were performed in which reverse transcriptase was not added to the samples to rule out contaminating DNA being responsible for any results.

\section{Statistical analysis}

All values were expressed as means \pm SE. Significance was assigned where $P<0.05$. Data sets were analyzed using Students $t$ test or using one-way ANOVA, with individual group means being compared with the Student-Newman-Keuls multiple comparison test.

\section{RESULTS}

\section{Effects of C5a on LPS-induced IL-6 production and gene transcription}

We investigated the effects of C5a on LPS-induced IL-6 production using purified blood neutrophils from healthy rats; $10 \mathrm{nM}$ C5a significantly enhanced LPS (20 ng/ml)-induced IL-6 
production in neutrophils at 2 and $4 \mathrm{~h}$ of in vitro stimulation (Fig. $1 A$ and $\underline{B}$ ). In these experiments, $2 \mathrm{~h}$ of in vitro stimulation caused measurable IL-6 levels in supernatant fluids only when neutrophils had been costimulated with C5a and LPS. At $4 \mathrm{~h}$ of incubation, the effect of C5a on LPS-induced IL-6 production was additive. To investigate whether these findings were due to transcriptional up-regulation of IL-6, RT-PCR experiments were conducted with total RNA from neutrophils stimulated similar to those in Fig. 1A. The data revealed C5a-induced gene transcription for IL-6, especially in the LPS + C5a group, suggesting that the effects of C5a were based on regulation of gene transcription of IL-6 in the presence of LPS (Fig. $1 C$ and $\underline{D}$ ).

\section{Effects of blockade of C5a/C5aR ativation on serum IL-6 levels during sepsis}

We sought to investigate the contribution of C5a and C5aR on IL-6 serum levels during CLPinduced sepsis in rodents. IL-6 serum levels in CLP rats peaked at $6 \mathrm{~h}$ after CLP (Fig. 2A). To investigate the possible contribution of neutrophils to IL-6 serum levels, experiments were conducted in neutrophil-depleted animals, using anti-neutrophil antibody or irrelevant IgG injected $18 \mathrm{~h}$ intraperitoneally before induction of CLP. In neutrophil-depleted animals, serum IL-6 levels were greatly reduced when compared with neutrophil-intact group, suggesting that neutrophils in some manner contribute directly or indirectly to the appearance of IL-6 in serum 6 $\mathrm{h}$ after CLP (Fig. $2 B$ ). We further investigated the relationship of C5a to IL-6 serum levels in animals using either control IgG or blocking IgG to C5a (anti-C5a), which was given intravenously at the start of CLP. The anti-C5a treated group showed significantly lower serum IL-6 levels 6 h CLP when compared with control IgG treated animals (Fig. 2C). To extend these results, we conducted similar experiments in $\mathrm{C} 5 \mathrm{aR}$-deficient mice. $\mathrm{C}_{5} \mathrm{aR}^{-/-}$animals showed sharply reduced IL-6 serum levels $6 \mathrm{~h}$ after CLP, when compared with $\mathrm{C} 5 \mathrm{aR}^{+/+}$mice (Fig. 2D). These data suggest an important linkage in sepsis between C5a, C5aR, and IL-6 production.

\section{NF- $\kappa$ B dependency of IL-6 production in neutrophils}

To address the question of whether IL-6 production in neutrophils was NF- $\kappa B$ dependent, we conducted experiments in which neutrophils had been preincubated with an NF-kB inhibitor (blocking IкB $\alpha$ phosphorylation) before stimulation with LPS and C5a. IL-6 production in rat neutrophils was completely suppressed with the NF-kB inhibitor (Fig. 3A). With the use of neutrophils from mice deficient in the NF- $\mathrm{KB}$ subunit, $\mathrm{p} 50$, neutrophils were stimulated in vitro with either buffer control or LPS (Fig. $3 B$ ). Neutrophils from p50 knockout mice and littermate controls produced similar levels of IL-6 after LPS stimulation when measured in cell supernatants, suggesting that IL-6 production in neutrophils was not dependent on the NF- $\mathrm{KB}$ subunit p50, even though IL-6 production is dependent on NF-אB activation (Fig. 3A). This is not too surprising since it is known that there are many active forms of NF- $\mathrm{kB}$, involving both homodimers and heterodimers.

\section{Effects of C5a and LPS on activation of MAPK pathways in neutrophils}

To investigate the underlying mechanisms for the observed effects of C5a in LPS-induced IL-6 production in neutrophils, we conducted Western blot experiments with whole cell lysates from rat blood neutrophils that had been stimulated in vitro with LPS, C5a, or the combination for various periods of time (5-60 min; Fig. 4). The data demonstrate that C5a caused rapid (within 5 min) phosphorylation of ERK1/2 (Fig. 4A), p38 (Fig. 4B), and p46 of JNK1/2 (Fig. 4C). In the 
case of ERK1/2 (Fig. 4A) and JNK (Fig. 4C), phosphorylation was transient and observed 5 min after in vitro stimulation but not at $15 \mathrm{~min}$ and thereafter. In contrast, p38 MAPK phosphorylation in C5a-exposed neutrophils was observed at $5 \mathrm{~min}$ and remained 15 and $30 \mathrm{~min}$ after in vitro stimulation with C5a (Fig. 4B). LPS alone did not appear to induce phosphorylation of ERK $1 / 2$ or JNK at any time point (Fig. $4 A$ and $\underline{C}$ ), although LPS-induced phosphorylation of p38 was observed after 15, 30, and $60 \mathrm{~min}$ of incubation. At the $2 \mathrm{~h}$ period of incubation, no phosphorylation of any of the kinases remained in any group (data not shown). These data suggest that $\mathrm{C} 5 \mathrm{a}$ is involved in rapid activation of all three kinase pathways and, in the case of p38, caused sustained (up to at least $1 \mathrm{~h}$ ) phosphorylation when cells were costimulated with LPS and C5a.

\section{Effects of signaling pathway inhibitors on IL-6 production in neutrophils}

The experiments in Fig. 4 indicated that $\mathrm{C} 5 \mathrm{a}$ could, after $4 \mathrm{~h}$ incubation with neutrophils, activate all three MAPK pathways, while LPS alone only activated p38 MAPK in rat neutrophils. Therefore, we investigated the ability of various signaling pathway inhibitors to block the enhancing C5a effects on LPS-induced IL-6 generation in neutrophils. After preincubation $37^{\circ} \mathrm{C}$ with various inhibitors for $30 \mathrm{~min}$, neutrophils from normal rats were stimulated in vitro for $4 \mathrm{~h}$ with C5a, LPS, or both. Doses of the kinase inhibitors were chosen at concentrations reported to fully suppress phosphorylation of the kinase pathway. Inhibition with a MEK1/2 (which is upstream of ERK1/2) inhibitor or an inhibitor of p38 resulted in greatly suppressed IL-6 production in neutrophils (Fig. 5A and $\underline{D}$ ). In these experiments, C5a induced phosphorylation of both ERK1/2 and p38. This phosphorylation was inhibited in cells pretreated with inhibitors of ERK1/2 or p38. High concentrations of the JNK1 inhibitor or the JNK2 inhibitor had limited or no inhibitory effects on IL-6 levels, even though C5a-induced phosphorylation of JNK was inhibited by both of these compounds (Fig. $5 B$ and $\underline{C}$ ). These results suggest that the enhancing effects of C5a on LPS-induced IL-6 production in neutrophils may be linked to phosphorylation of ERK1/2 and p38 MAPK but not JNK1/2.

\section{Effects of combined inhibition of p38 and ERK1/2 on LPS-induced IL-6 production in neutrophils}

The experiments depicted in Fig. 5 indicated that LPS-induced IL-6 production in neutrophils required p38 and ERK1/2 activation. To further investigate the contribution of these pathways for C5a- and LPS-induced IL-6 production, we conducted similar experiments in which neutrophils were preincubated with increasing concentrations of each inhibitor and then stimulated, as depicted in Fig. $6 A$ and $\underline{B}$. IL-6 production with inhibition of either MEK1/2 or p38 was dose dependent on the concentration of the inhibitor, with progressive inhibition of LPS-induced IL-6 production in neutrophils. Preincubation of neutrophils with the combination of inhibitors of MEK1/2 $(1 \mu \mathrm{M})$ and p38 $(0.1 \mu \mathrm{M})$ resulted in additive suppression of IL-6 generation in neutrophils (Fig. 6C). Under such conditions, C5a still elicited significant additive effects on LPS-induced production. These data suggest that both p38 and ERK1/2 pathways are involved in LPS-induced production of IL-6 in neutrophils. 


\section{DISCUSSION}

IL-6 production during experimental sepsis has recently been demonstrated to be harmful in rodents (12). IL-6 production appeared to be closely linked to up-regulation of C5aR in various organs during sepsis, which might explain the harmful effects of IL-6 during sepsis and might be linked to multi-organ failure (6). In the current study, we demonstrate that LPS-induced IL-6 production in neutrophils is amplified in the co-presence of $\mathrm{C} 5 \mathrm{a}$ (Fig. 1). We further demonstrate that in vivo serum levels of IL-6 are clearly reduced when C5a is blocked or, alternatively, when $\mathrm{C} 5 \mathrm{aR}$ is genetically absent (Fig. 2). Neutrophil-depleted animals showed clear evidence of reduced serum levels of IL-6 hours after CLP, suggesting that at this time point, neutrophils may be directly or indirectly linked to elevated serum levels of IL-6. It seems possible that early C5a generation during sepsis may lead to significantly enhanced IL-6 production by neutrophils and other cells (20), which, in turn, will cause C5aR up-regulation in various organs, possibly setting the stage for increased susceptibility toward C5a-related multi-organ failure (11).

C5a induced enhancement of LPS-induced IL-6 production in vitro has been described in monocytes (14) in which IL-6 generation was found to be NF- $\kappa$ B dependent (21) and required activation of the ERK pathway as well as JNK pathway (17). Similarly, C3a and N-formyl-MetLeu-Phe (fMLP) enhanced IL-6 production in peripheral blood mononuclear cells $(20,22)$, suggesting a common pattern for G-protein coupled receptor mediated regulation of cytokine production in these cells. C5a has been reported to induce NF- $\mathrm{B}$ activation in monocytes (18). In neutrophils, LPS has been shown to induce p38 activation (23). However, little is known about the effects of $\mathrm{C} 5 \mathrm{a}$ on regulation of cytokine production in neutrophils or the signaling pathways leading to IL-6 production in neutrophils.

LPS-induced IL-6 production in neutrophils was dependent on NF- $\kappa$ B activation (but not on the presence of its subunit, p50; Fig. 3) and was also dependent on p38 activation as well as ERK1/2 activation (phosphorylation) (Figs. 5 and $\underline{6}$ ) but not on engagement of JNK1/2. In tubular epithelial cells of the kidney, LPS-induced generation of IL-6 was dependent on activation of both p38 MAPK and ERK (24). Similar findings have been made in human osteoblasts, but in these cells IL-6 production was dependent on AP-1 activation and not on NF- $\mathrm{B}$ activation (25), suggesting that different cell types employ different transcription factors for IL-6 synthesis even though the same MAPK pathways are involved. It is possible that activation of ERK1/2 and p38 results in a final common step involving activation of mitogen and stress activated kinase $1 / 2$ (MSK1/2) (26), the end result of which is IL-6 production.

To understand the underlying mechanisms for the additive effects of C5a on LPS-induced IL-6 production in neutrophils in greater detail, we investigated the effects of C5a on activation of various signaling pathways in neutrophils. We found that $\mathrm{C} 5 \mathrm{a}$ caused rapid phosphorylation of all three pathways (p38, ERK1/2, and JNK), with phosphorylation usually being brief or in the case of p38 being longer lasting (Fig. 4). However, when signaling pathways were blocked by specific inhibitors, the enhancing effects of C5a on LPS-induced IL-6 production could still be observed, albeit reduced (Figs. 5 and $\underline{6}$ ). We interpret these data to suggest that C5a causes enhanced phosphorylation and activation of p38 and ERK1/2, thereby enhancing LPS-induced IL-6 production via NF- $\kappa \mathrm{B}$ activation. 
We have recently demonstrated that compromised innate immune functions of neutrophils $\left(\mathrm{H}_{2} \mathrm{O}_{2}\right.$ production, chemotaxis, and phagocytosis) during sepsis are restored in rodents undergoing antibody-induced blockade of $\mathrm{C} 5 \mathrm{a}(11,27)$. It seems that $\mathrm{C} 5 \mathrm{a}$ might be responsible for compromised neutrophil function during human sepsis (28). Recent findings by our group suggest that C5a stimulation of neutrophils leads to decreased LPS-induced TNF- $\alpha$ production in neutrophils, whereas in alveolar macrophages, C5a exerts the opposite effect, namely, increases LPS-induced TNF- $\alpha$ production (29). These and other findings in neutrophils underscore their unique role and importance during the onset of sepsis. Our data suggest that neutrophils may directly or indirectly be a significant source of serum IL-6 appearing during sepsis.

In conclusion, we report the enhancing effects of C5a on LPS-induced IL-6 production in neutrophils and the systemic implications of this phenomenon during the onset of sepsis. C5a may have significant affects on mediator-induced production of IL-6 in neutrophils, linked to $\mathrm{C} 5 \mathrm{a}$ involvement in rapid activation of various signaling pathways that lead to NF- $\mathrm{B}$ activation and are essential for IL- 6 generation by neutrophils. There is now accumulating evidence for an important role of $\mathrm{C} 5 \mathrm{a}$ for regulation of neutrophil functions and mediator production during sepsis. Understanding the underlying intracellular mechanisms for the regulatory roles of C5a may lead to new therapeutic targets for the treatment of sepsis.

\section{ACKNOWLEDGMENTS}

The work was supported by: National Institutes of Health and National Heart, Lung, and Blood Institute Grants: GM-29507, HL-31963, GM-61656, and AI-25011.

\section{REFERENCES}

1. Shin, H. S., Snyderman, R., Friedman, E., Mellors, A., and Mayer, M. M. (1968) Chemotactic and anaphylatoxic fragment cleaved from the fifth component of guinea pig complement. Science 162, 361-363

2. Goldstein, I. M., and Weissmann, G. (1974) Generation of C5-derived lysosomal enzymereleasing activity (C5a) by lysates of leukocyte lysosomes. J. Immunol. 113, 1583-1588

3. Sacks, T., Moldow, C. F., Craddock, P. R., Bowers, T. K., and Jacob, H. S. (1978) Oxygen radicals mediate endothelial cell damage by complement-stimulated granulocytes. An in vitro model of immune vascular damage. J. Clin. Invest. 61, 1161-1167

4. Schumacher, W. A., Fantone, J. C., Kunkel, S. E., Webb, R. C., and Lucchesi, B. R. (1991) The anaphylatoxins $\mathrm{C} 3 \mathrm{a}$ and $\mathrm{C} 5 \mathrm{a}$ are vasodilators in the canine coronary vasculature in vitro and in vivo. Agents Actions 34, 345-349

5. Guo, R. F., Huber-Lang, M., Wang, X., Sarma, V., Padgaonkar, V. A., Craig, R. A., Riedemann, N. C., McClintock, S. D., Hlaing, T., Shi, M. M., et al. (2000) Protective effects of anti-C5a in sepsis-induced thymocyte apoptosis. J. Clin. Invest. 106, 1271-1280

6. Riedemann, N. C., Guo, R. F., Neff, T. A., Laudes, I. J., Keller, K. A., Sarma, J. V., Markiewski, M. M., Mastellos, D., Strey, C. W., Pierson, C. L., et al. (2002) increased C5a receptor expression in sepsis. J. Clin. Invest. 110, 101-108 
7. de Boer, J. P., Creasey, A. A., Chang, A., Roem, D., Eerenberg, A. J., Hack, C. E., and Taylor, F. B., Jr. (1993) Activation of the complement system in baboons challenged with live Escherichia coli: correlation with mortality and evidence for a biphasic activation pattern. Infect. Immun. 61, 4293-4301

8. Smedegard, G., Cui, L. X., and Hugli, T. E. (1989) Endotoxin-induced shock in the rat. A role for C5a. Am. J. Pathol. 135, 489-497

9. Nakae, H., Endo, S., Inada, K., Takakuwa, T., Kasai, T., and Yoshida, M. (1994) Serum complement levels and severity of sepsis. Res. Commun. Chem. Pathol. Pharmacol. 84, 189-195

10. Czermak, B. J., Sarma, V., Pierson, C. L., Warner, R. L., Huber-Lang, M., Bless, N. M., Schmal, H., Friedl, H. P., and Ward, P. A. (1999) Protective effects of C5a blockade in sepsis. Nat. Med. 5, 788-792

11. Huber-Lang, M., Sarma, V. J., Lu, K. T., McGuire, S. R., Padgaonkar, V. A., Guo, R. F., Younkin, E. M., Kunkel, R. G., Ding, J., Erickson, R., et al. (2001) Role of C5a in multiorgan failure during sepsis. J. Immunol. 166, 1193-1199

12. Riedemann, N. C., Neff, T. A., Guo, R. F., Bernacki, K. D., Laudes, I. J., Sarma, J. V., Lambris, J. D., and Ward, P. A. (2003) Protective effects of IL-6 blockade in sepsis are linked to reduced C5a receptor expression. J. Immunol. 170, 503-507

13. Mack, C., Jungermann, K., Gotze, O., and Schieferdecker, H. L. (2001) Anaphylatoxin C5a actions in rat liver: synergistic enhancement by $\mathrm{C} 5 \mathrm{a}$ of lipopolysaccharide-dependent alpha(2)-macroglobulin gene expression in hepatocytes via IL-6 release from Kupffer cells. J. Immunol. 167, 3972-3979

14. Montz, H., Koch, K. C., Zierz, R., and Gotze, O. (1991) The role of C5a in interleukin-6 production induced by lipopolysaccharide or interleukin-1. Immunology 74, 373-379

15. McDonald, P. P., Bald, A., and Cassatella, M. A. (1997) Activation of the NF-kappaB pathway by inflammatory stimuli in human neutrophils. Blood 89, 3421-3433

16. Nick, J. A., Avdi, N. J., Young, S. K., Lehman, L. A., McDonald, P. P., Frasch, S. C., Billstrom, M. A., Henson, P. M., Johnson, G. L., and Worthen, G. S. (1999) Selective activation and functional significance of p38alpha mitogen-activated protein kinase in lipopolysaccharide-stimulated neutrophils. J. Clin. Invest. 103, 851-858

17. Tuyt, L. M., Dokter, W. H., Birkenkamp, K., Koopmans, S. B., Lummen, C., Kruijer, W., and Vellenga, E. (1999) Extracellular-regulated kinase 1/2, Jun N-terminal kinase, and c-Jun are involved in NF-kappa B-dependent IL-6 expression in human monocytes. J. Immunol. 162, 4893-4902

18. Pan, Z. K. (1998) Anaphylatoxins C5a and C3a induce nuclear factor kappaB activation in human peripheral blood monocytes. Biochim. Biophys. Acta 1443, 90-98 
19. Huber-Lang, M. S., Sarma, J. V., McGuire, S. R., Lu, K. T., Guo, R. F., Padgaonkar, V. A., Younkin, E. M., Laudes, I. J., Riedemann, N. C., Younger, J. G., et al. (2001) Protective effects of anti-C5a peptide antibodies in experimental sepsis. FASEB J. 15, 568-570

20. Fischer, W. H., Jagels, M. A., and Hugli, T. E. (1999) Regulation of IL-6 synthesis in human peripheral blood mononuclear cells by C3a and C3a(desArg). J. Immunol. 162, 453-459

21. Ray, A., and Ray, B. K. (1995) Lipopolysaccharide-mediated induction of the bovine interleukin-6 gene in monocytes requires both NF-kappa $\mathrm{B}$ and $\mathrm{C} / \mathrm{EBP}$ binding sites. $D N A$ Cell Biol. 14, 795-802

22. Arbour, N., Tremblay, P., and Oth, D. (1996) N-formyl-methionyl-leucyl-phenylalanine induces and modulates IL-1 and IL-6 in human PBMC. Cytokine 8, 468-475

23. Yan, S. R., Al-Hertani, W., Byers, D., and Bortolussi, R. (2002) Lipopolysaccharide-binding protein- and CD14-dependent activation of mitogen-activated protein kinase p38 by lipopolysaccharide in human neutrophils is associated with priming of respiratory burst. Infect. Immun. 70, 4068-4074

24. Leonard, M., Ryan, M. P., Watson, A. J., Schramek, H., and Healy, E. (1999) Role of MAP kinase pathways in mediating IL-6 production in human primary mesangial and proximal tubular cells. Kidney Int. 56, 1366-1377

25. Kondo, A., Koshihara, Y., and Togari, A. (2001) Signal transduction system for interleukin6 synthesis stimulated by lipopolysaccharide in human osteoblasts. J. Interferon Cytokine Res. 21, 943-950

26. Yu, M., Blomstrand, E., Chibalin, A. V., Krook, A., and Zierath, J. R. (2001) Marathon running increases ERK1/2 and p38 MAP kinase signalling to downstream targets in human skeletal muscle. J. Physiol. 536, 273-282

27. Huber-Lang, M. S., Younkin, E. M., Sarma, J. V., McGuire, S. R., Lu, K. T., Guo, R. F., Padgaonkar, V. A., Curnutte, J. T., Erickson, R., and Ward, P. A. (2002) Complementinduced impairment of innate immunity during sepsis. J. Immunol. 169, 3223-3231

28. Solomkin, J. S., Jenkins, M. K., Nelson, R. D., Chenoweth, D., and Simmons, R. L. (1981) Neutrophil dysfunction in sepsis. II. Evidence for the role of complement activation products in cellular deactivation. Surgery 90, 319-327

29. Riedemann, N. C., Guo, R. F., Bernacki, K. D., Reuben, J., Laudes, I. J., Neff, T. A., Gao, H., Speyer, C., Sarma, J. V., Zetoune, F. S., et al. (2003) Regulation by C5a of neutrophil activation during sepsis. Immunity 19, 193-202 
Fig. 1

\section{A Neutrophil supernatants}

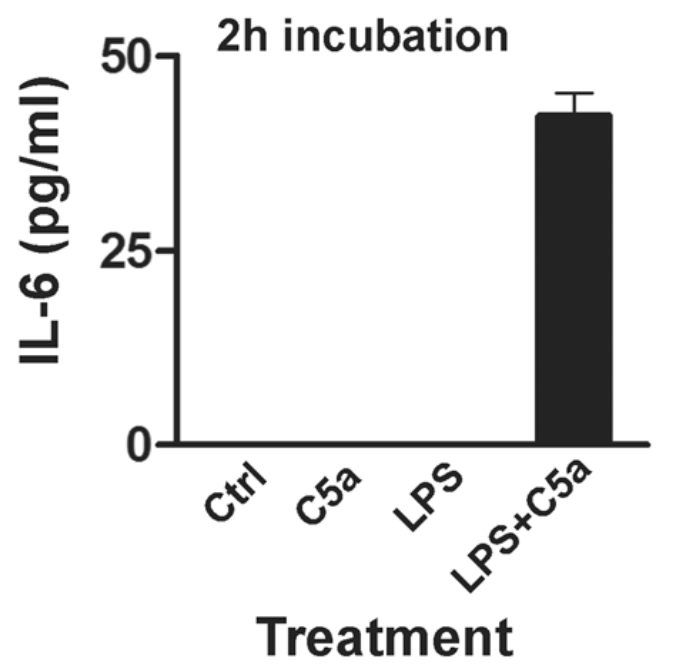

\section{Neutrophil RT-PCR}

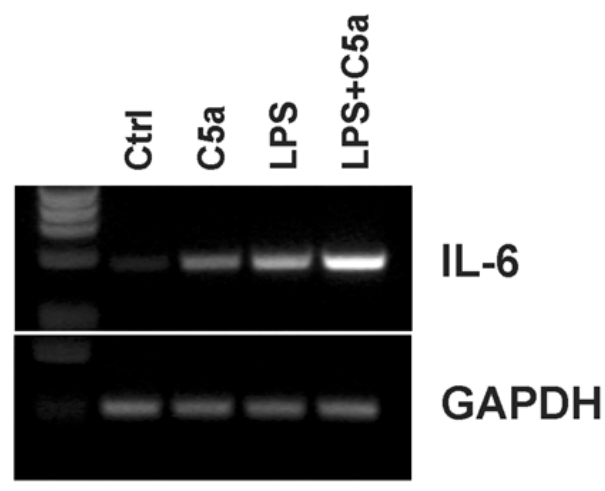

\section{B Neutrophil supernatants}

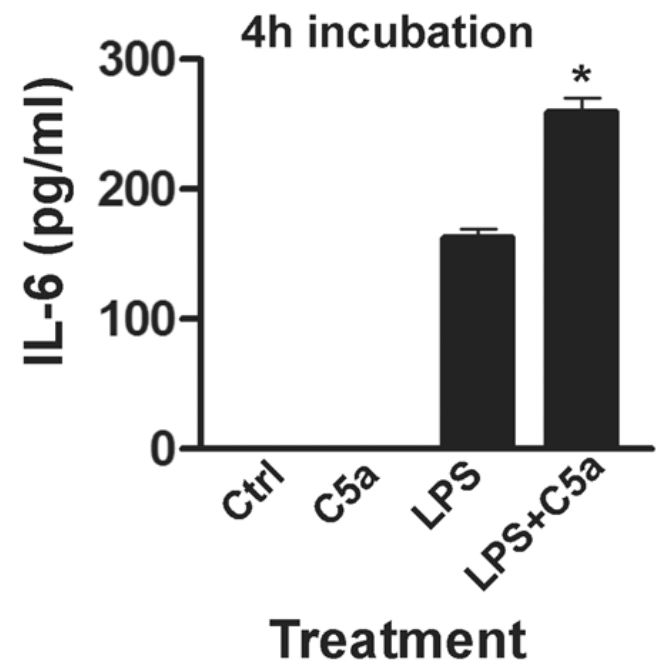

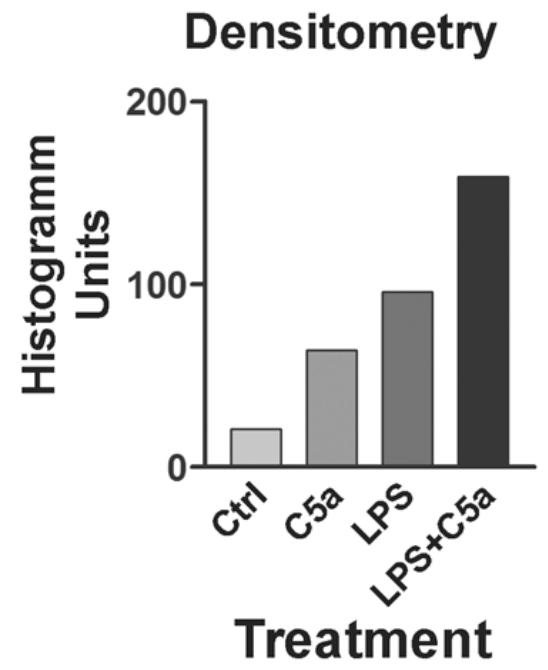

Figure 1. C5a effects on LPS-induced IL-6 production and gene transcription in neutrophils. ELISA experiments from neutrophil supernatant fluids $(\boldsymbol{A}, \boldsymbol{B})$. Neutrophils were isolated from rat blood; $4 \times 10^{6}$ cells $/ \mathrm{ml}$ were then incubated in vitro with C5a $(10 \mathrm{nM})$, LPS $(20 \mathrm{ng} / \mathrm{ml})$, or C5a + LPS for $2 \mathrm{~h}(\boldsymbol{A})$ or $4 \mathrm{~h}(\boldsymbol{B})$ at $37^{\circ} \mathrm{C}$. Data are representative of 4 independent experiments with neutrophils being pooled from 6-8 animals per study; incubation and analysis were carried out in separate quadruplicate samples. $C$ ) RT-PCR experiments with total RNA from rat neutrophils, stimulated as depicted with concentrations (as described in the text) for $2 \mathrm{~h}$ at $37^{\circ} \mathrm{C}$. Shown are results for IL- 6 gene transcription and GAPDH as a loading control, as well as accompanying densitometry analysis. $D$ ) Densitometric measurements of the Northern blot $(\boldsymbol{C})$. Each dataset is representative of 2 independent experiments with neutrophils pooled from 8 rats per study. 
Fig. 2
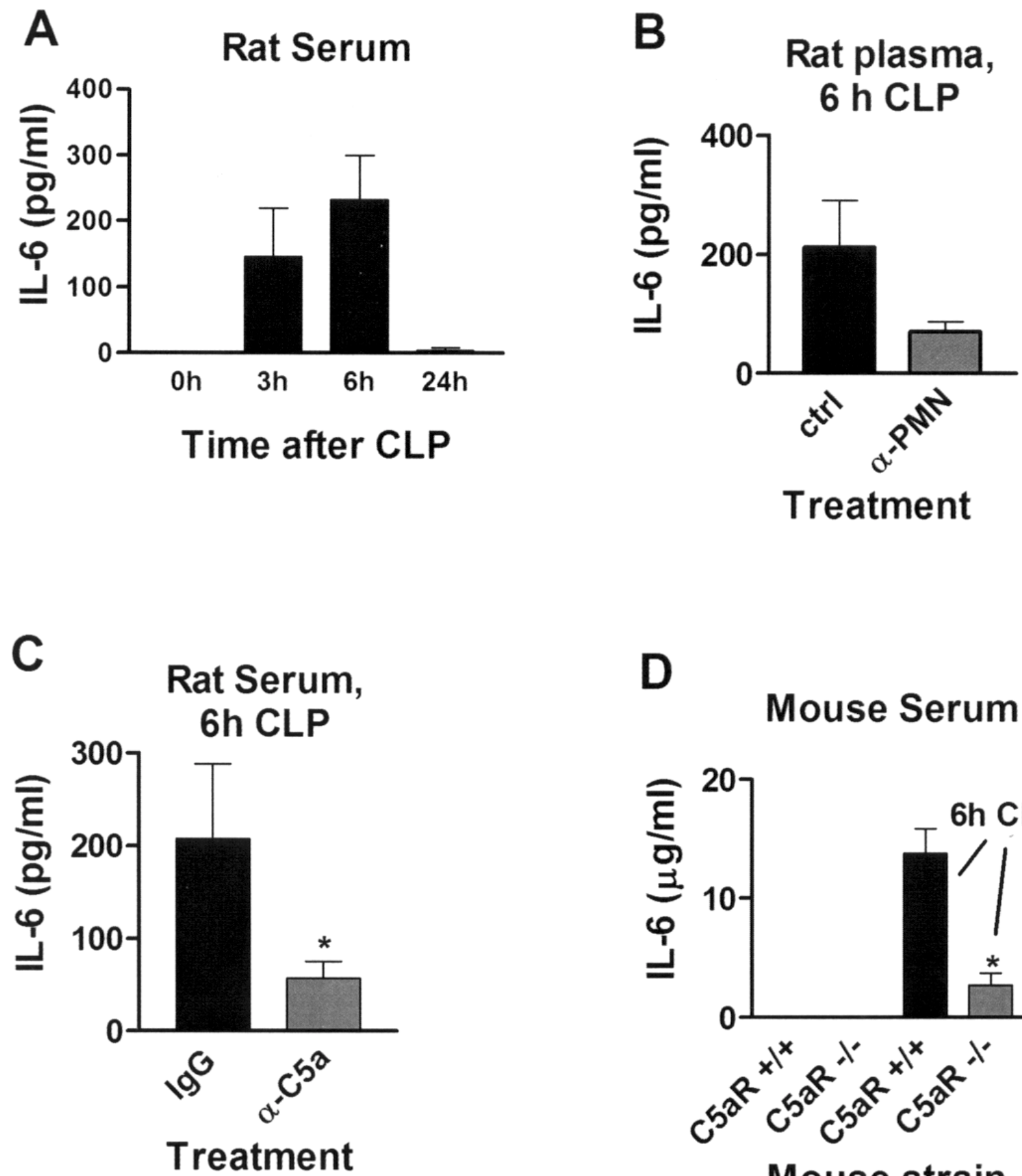

D

\section{Mouse Serum}

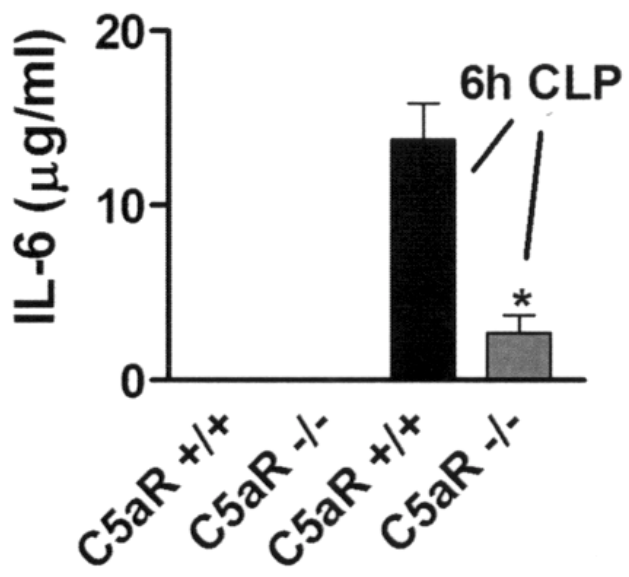

Mouse strain

Figure 2. Effects of blockade of C5a/C5aR activation on serum IL-6 levels during sepsis. A) ELISA analysis of rat serum samples at various time points after CLP. Data are representative of 4-6 different serum samples per group. B) ELISA analysis of plasma samples for IL-6 from neutrophil-depleted rats $6 \mathrm{~h}$ after CLP. Neutrophil-depletion was achieved by intraperitoneal injection of anti-neutrophil antibody $18 \mathrm{~h}$ before CLP. Data are representative of 4-5 animals per group. C) IL-6 ELISA analysis of rat serum samples $6 \mathrm{~h}$ after CLP in animals treated intravenously with anti-C5a IgG $(500 \mu \mathrm{g} / \mathrm{rat})$ or equal amounts of irrelevant IgG at the start of CLP. Data are representative of 6 different serum samples per group. D) IL-6 ELISA analysis of serum samples from $\mathrm{C}_{5} \mathrm{aR}^{-/-}$and $\mathrm{C}^{2} \mathrm{aR}^{+/+}$mice $6 \mathrm{~h}$ after CLP. Data are representative of 4 different animals per group. 
Fig. 3
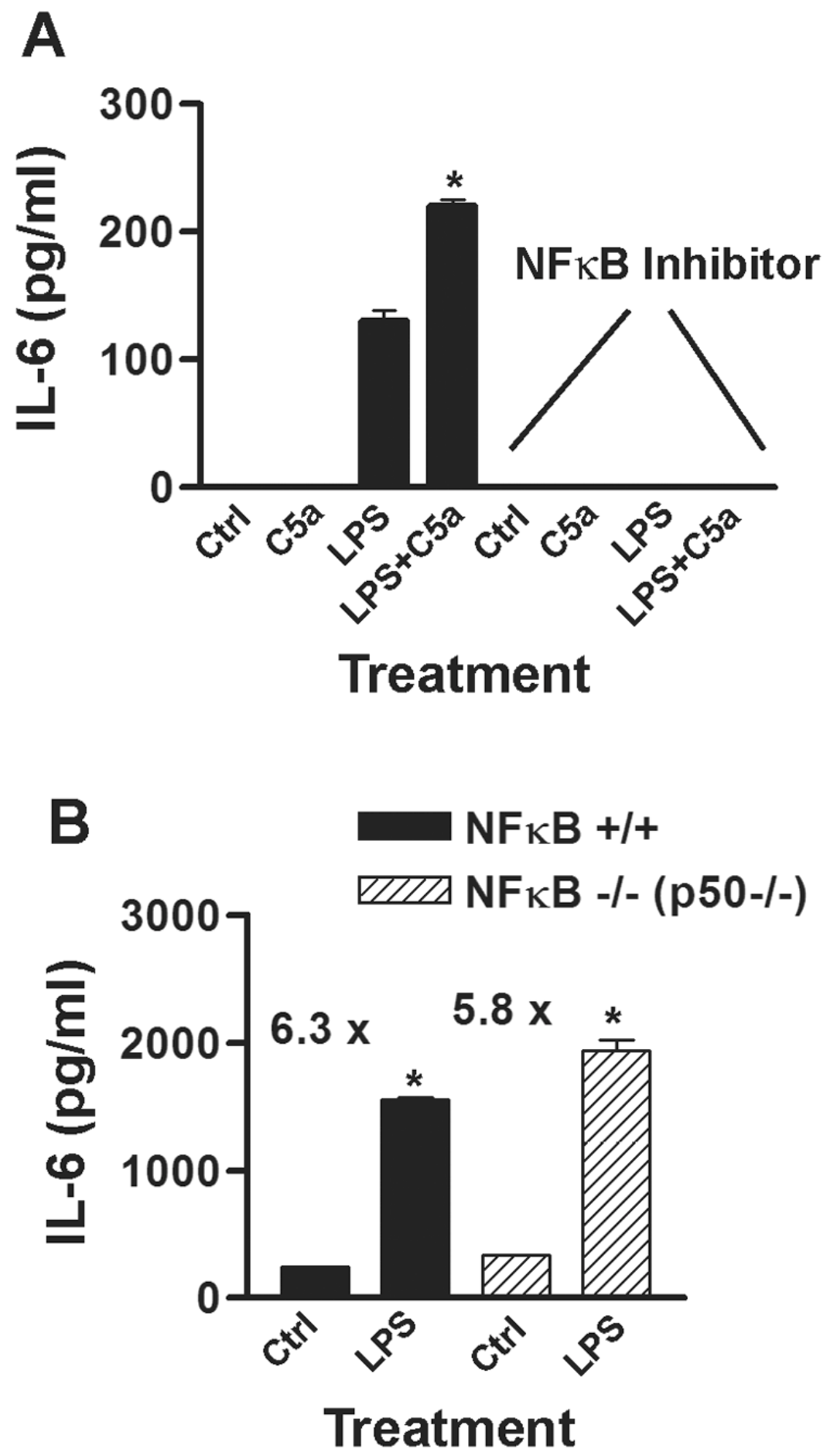

Figure 3. NF-kB dependency of IL-6 production in neutrophils. $A$ ) ELISA analysis for IL-6 content from rat neutrophils stimulated for $4 \mathrm{~h}$ at $37^{\circ} \mathrm{C}$ as depicted, with agonist concentrations similar to those described in Fig. 1. Neutrophils were prestimulated with either DMSO control or $20 \mu \mathrm{M} N F-\kappa B$ inhibitor (Bay 11-7082) for 30 min before stimulation. Data are representative of 2 independent experiments. Neutrophils were pooled from 6-8 donor animals per study; incubation and analysis were carried out with quadruplicate samples. B) ELISA analysis of mouse IL-6 in supernatant fluids from peritoneal neutrophils stimulated with LPS $(20 \mathrm{ng} / \mathrm{ml})$, LPS + C5a $(10 \mathrm{nM})$ or buffer control for $4 \mathrm{~h}$ at $37^{\circ} \mathrm{C}$. Fluids from neutrophils of NF- $\mathrm{BB}-/-$ (p50 deficient) mice and NF- $\mathrm{\kappa B}+/+$ mice were analyzed. Data are representative of experiments with neutrophils pooled from 3 mice and carried out in separate quadruplicates. 
Fig. 4
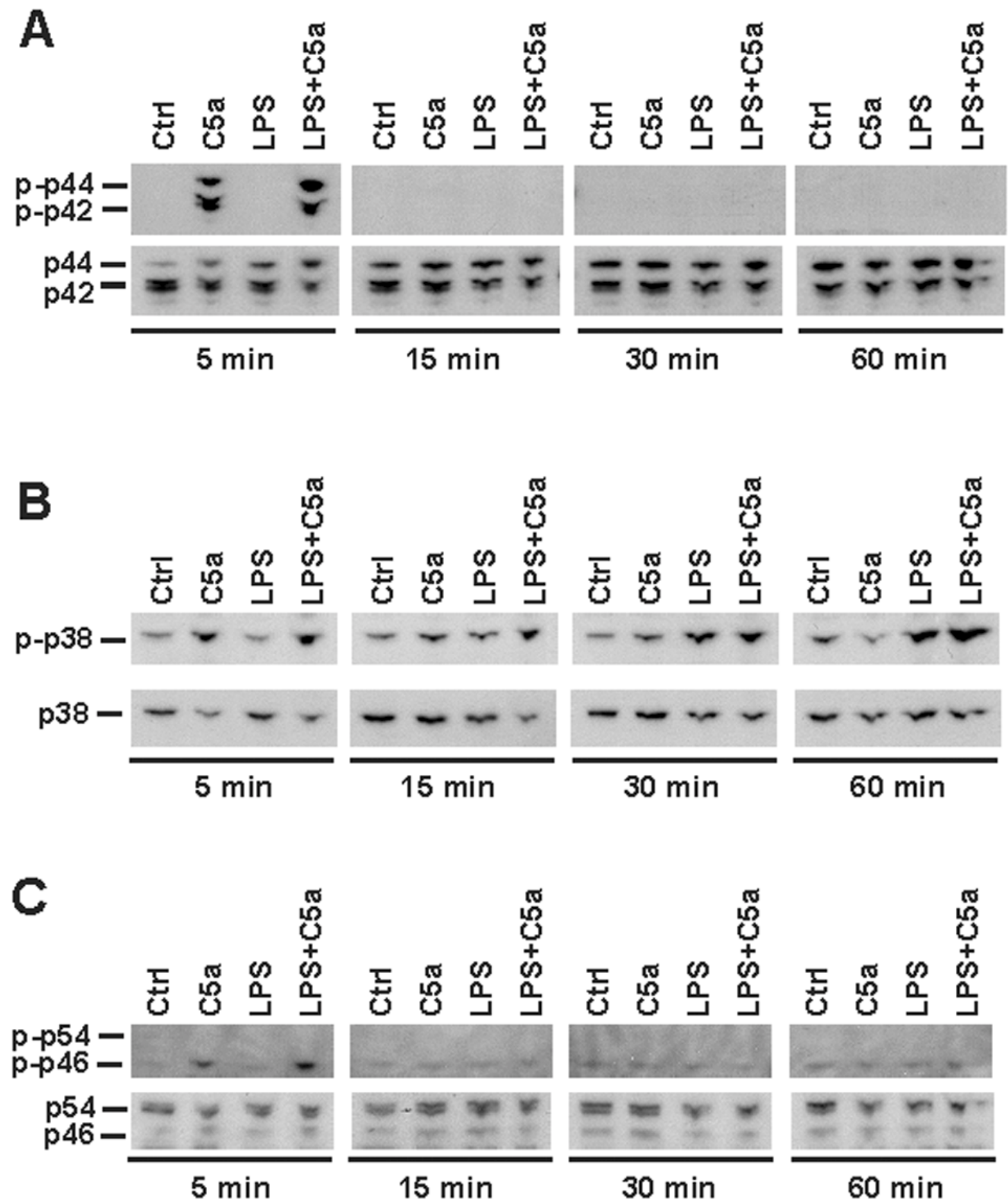

Figure 4. Effects of C5a and LPS on activation of MAPK pathways in neutrophils. Western blot analysis of neutrophil whole cell lysates from cells stimulated for various time points (as depicted) at $37^{\circ} \mathrm{C}$ with C5a (10 nM), LPS (20 $\mathrm{ng} / \mathrm{ml}$ ), or both. Activation (presence of phosphorylated forms) is demonstrated in ERK1/2 (p44, p42) (A), p38 MAPK (B), and JNK1/2 (p54, p46) $(\boldsymbol{C})$. The blots are representative for 2-3 independent experiments, each conducted with neutrophils pooled from 4-6 rats. 
Fig. 5
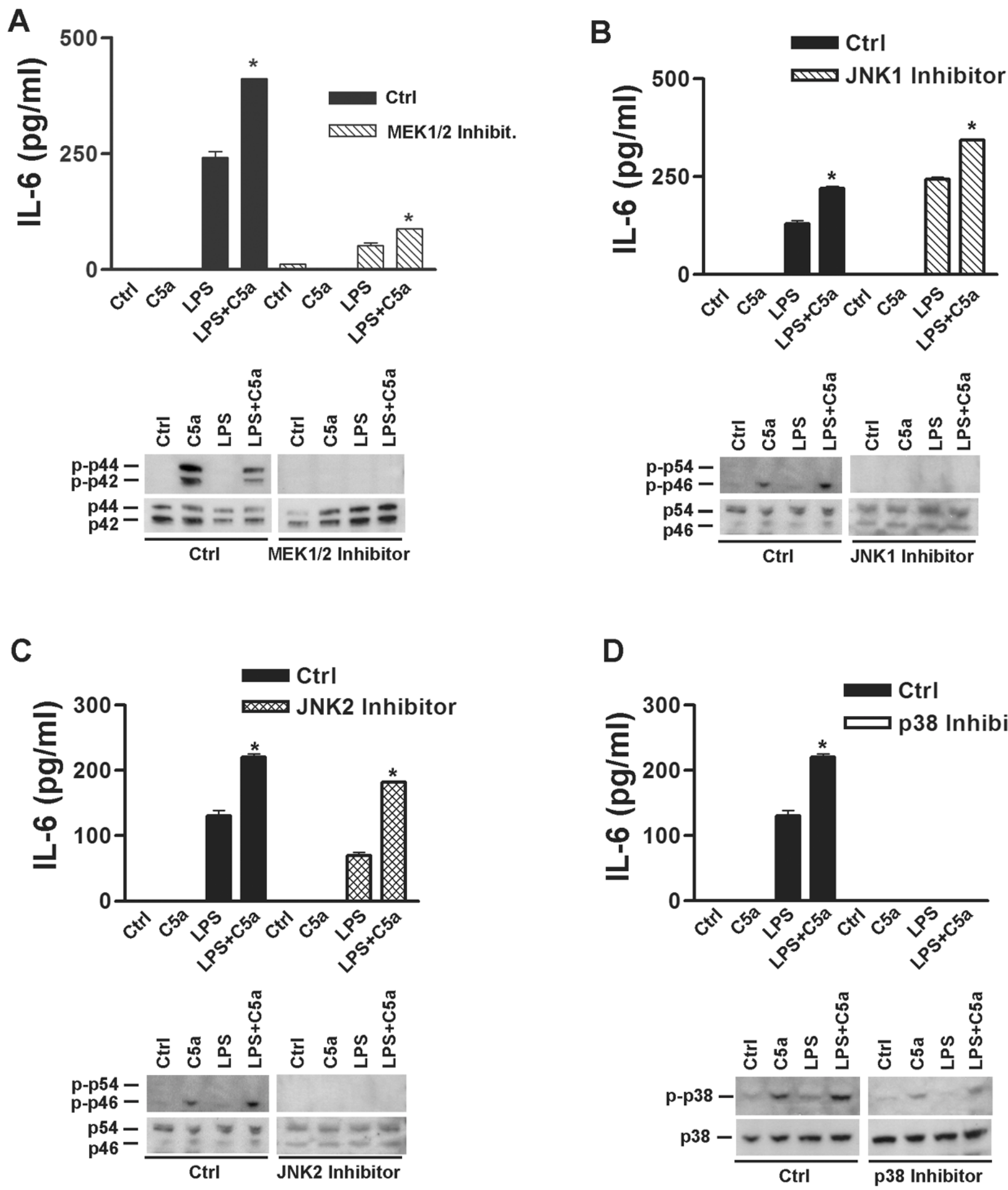

Figure 5. Effects of MAPK pathway inhibitors on IL-6 production in neutrophils. ELISA analysis for IL-6 in rat neutrophil supernatant fluids after $4 \mathrm{~h}$ stimulation at $37^{\circ} \mathrm{C}$ with C5a $(10 \mathrm{nM})$, LPS $(20 \mathrm{ng} / \mathrm{ml})$, or both, and accompanying Western blots from matching whole cell lysates of neutrophils stimulated, as indicated, for $5 \mathrm{~min}$. $\boldsymbol{A}$ ) Effects of preincubation for $30 \mathrm{~min}$ with $20 \mu \mathrm{M}$ MEK1/2 inhibitor (U0126). B) Effects of preincubation for 30 min with $5 \mu \mathrm{M}$ JNK-1 inhibitor 1 (L-form peptide). $\boldsymbol{C}$ ) Effects of preincubation for 30 min with $20 \mu \mathrm{M}$ JNK-2 inhibitor 2 (SP600125). D) Effects of preincubation for 30 min with $20 \mu \mathrm{M}$ p38 MAPK inhibitor (SB203580). Data are representative of 2-3 independent experiments with neutrophils pooled from 4-6 rats and stimulated in separate triplicates. *Statistical significant difference from the LPS-only treated group. 
Fig. 6
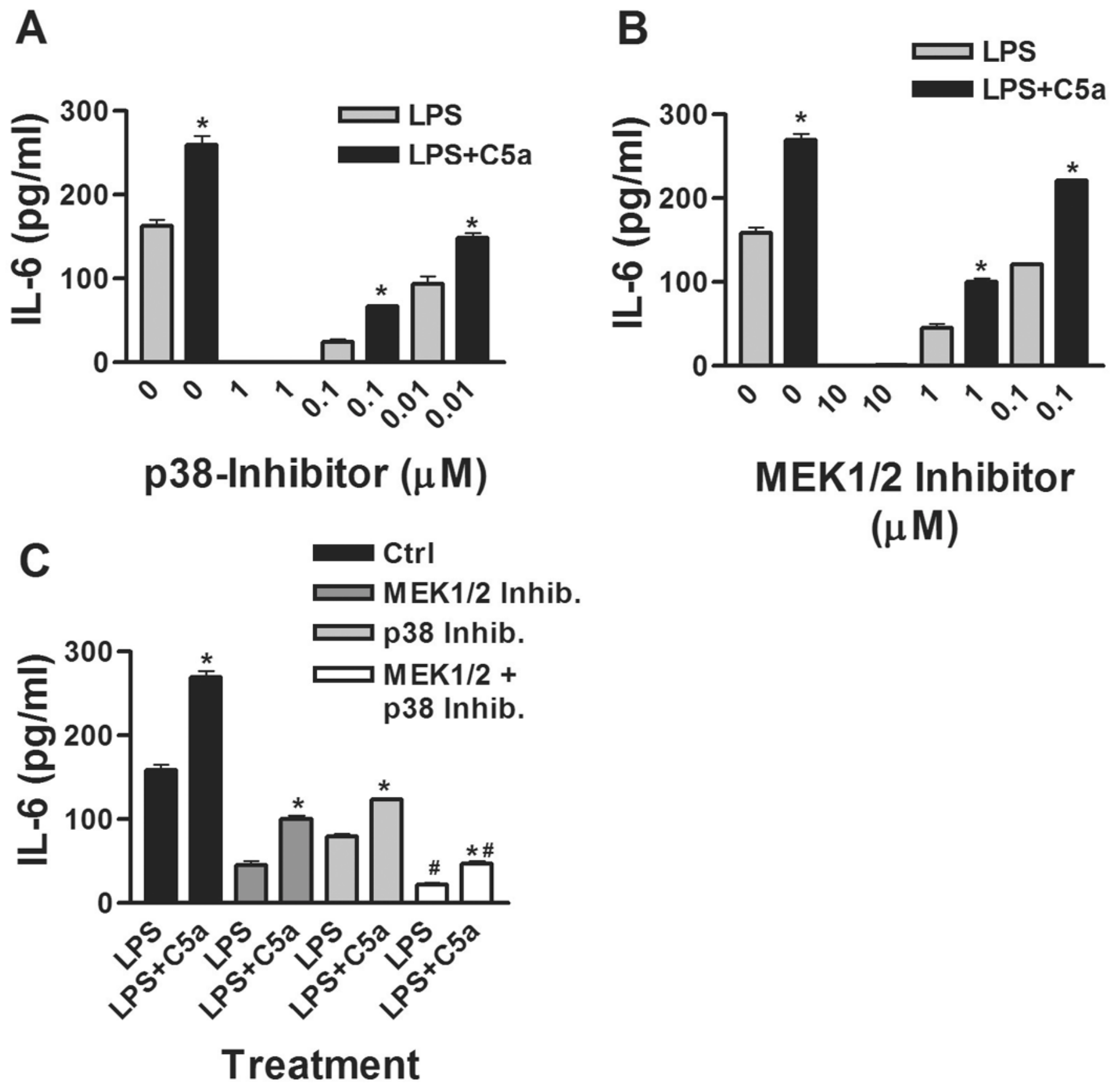

MEK1/2 Inhibitor $(\mu \mathrm{M})$

Figure 6. Effects of p38 and ERK1/2 inhibition on LPS-induced IL-6 production by neutrophils. ELISA analysis for IL-6 supernatant fluids from rat neutrophils. Cells were stimulated in vitro for $4 \mathrm{~h}$ at $37^{\circ} \mathrm{C}$ with LPS $(20 \mathrm{ng} / \mathrm{ml})$, or LPS plus C5a $(10 \mathrm{nM}) . \boldsymbol{A}$ ) Effects of pretreatment of neutrophils for $30 \mathrm{~min}$ with various doses of p38 MAPK inhibitor (SB203580). B) Effects of pretreatment of neutrophils for $30 \mathrm{~min}$ with various doses of MEK1/2 inhibitor (U0126). C) Effects of pretreatment for 30 min with p38 MAPK inhibitor $(0.1 \mu \mathrm{M})$, MEK1/2 inhibitor $(1 \mu \mathrm{M})$, or both. *Significant statistical differences between the LPS and the C5a + LPS treated groups. \#Significant statistical difference of the combined (p38 + MEK1/2) inhibitors as compared with the single inhibitor (either p38 or MEK1/2). Data are representative of 2-3 independent experiments with neutrophils pooled from 4-6 rats. Stimulation and analysis were carried out using triplicate samples. 